\title{
Mechanical Behavior of an Industrial Gas Turbine under Fault Conditions, a Case History*
}

\author{
STEFAN S. FLORJANCIC ${ }^{a, \dagger}$, NOEL LIVELY $^{\mathrm{b}}$ and RICHARD THOMAS ${ }^{\mathrm{c}}$ \\ a ABB Power Generation, CH-5401 Baden, Switzerland; ' Kentucky Utilities Company, E.W. Brown Generation Construction, \\ Burgin, KY 40301, USA; ${ }^{\mathrm{c} B e n t l y ~ N e v a d a ~ M a c h i n e r y ~ D i a g n o s t i c ~ S e r v i c e s, ~ B a t o n ~ R o u g e, ~ L A ~ 70817, ~ U S A ~}$
}

(Received 24 April 1998; Revised 5 May 1998; In final form 7 July 1998)

\begin{abstract}
The resolve of journal bearing field problems and the full vibrational assessment of an industrial gas turbine, simple cycle rotor train, ABB's GT11N2 is presented. Three units experienced several times damage of the journal bearings on the compressor end. The analysis of the damage, including tests, indicated that insufficient jacking oil flow was the cause. The jacking concept was corrected and starting history has proven reliable operation, resulting in not one additional failure.

During the same period, two last stage blades failed in one of the units damaging neighboring blades additionally. The machine tripped under the unbalance. Some auxiliary piping and the babbitt of the journal bearing was damaged. However, the rotor came to a safe stop with only some rubbing, and the turbine casing fulfilled its containment function perfectly.

In order to better understand the dynamic behavior of the train, an extensive vibration measurement program was decided between Kentucky Utilities and ABB, and executed by Bently Nevada. The results proved excellent rotor balance, verified original design parameters, and no fluid induced instabilities were found. This joint effort allowed to fully assess and prove the rotor dynamic integrity of the gas turbine.
\end{abstract}

Keywords: Case history, Journal bearings, Rotordynamics, Unbalance, Vibration measurement, Instability

\section{INTRODUCTION}

Three ABB GT11N2s, an upgrade of the proven GT11N1, went into commissioning at Kentucky Utilities (KU) during 1994. In the beginning of 1995 , after a significant number of starts had been accumulated on the fleet, it was realized that the most loaded journal bearing on the compressor end was damaged several times on various units. The analysis of the journal damage, including tests in the spin pit, indicated that insufficient jacking oil flow during start up and shut down was the cause. The jacking concept was corrected by a higher flow oil pump and the subsequent starting history has

* This paper was originally presented at ISROMAC-7.

${ }^{\dagger}$ Corresponding author. Tel.: 0562057516 . Fax: 0562054690. 
conclusively proven that these strongly loaded journal bearings can operate very reliably, as not one additional failure has occurred.

At the end of the same period, two last stage blades of one of the machines failed due to simultaneous high stochastic excitation at two natural frequencies. Neighboring blades were damaged additionally, resulting in a big unbalance. The excessive vibrations caused the machine to trip immediately, and the turbine casing fulfilled its containment function perfectly. Due to high vibrations some auxiliary piping was damaged, leading to the loss of lube oil and the destruction of the babbitt in the journal bearing liner. However, the rotor came to a safe stop, and only some rubbing and burrs had to be rectified on this part.

At this stage, it was decided between $\mathrm{KU}$ and $\mathrm{ABB}$, to launch an extensive vibration measurement program including unbalance testing in order to better understand the dynamic behavior of the machine and the damage and rubbing pattern of the train. This program was contracted to Bently Nevada Corporation (BNC), with extensive infrastructure support of $\mathrm{KU}$, and definitions and supervision of the measurement by ABB. The results of the measurement proved excellent rotor balance, and verified original assumptions on rotordynamic design parameters. Additionally, it was found that there are absolutely no fluid induced instabilities. The joint effort of the owner, the OEM and the contracted vibration measurement consultants allowed to fully assess and prove the rotor dynamic integrity of the gas turbine.

\section{PLANT DESCRIPTION, COMMISSIONING PHASE, AND BEARING FAILURES}

The E.W. Brown Combustion Turbine Generating Facility is a peaking plant located about $56 \mathrm{~km}$ (35 miles) southwest of Lexington, KY adjacent to an existing coal fired steam generating plant. The peaking station is designed to be unmanned with minimal physical connections to the steam plant, and is built around four simple cycle ABB GT11N2 machines (Fig. 1) the first two planned for commercial operation in 1994, followed by one each in 1995 and 1996. The primary fuel is natural gas backed up by \#2 liquid fuel, with water injection controlled $\mathrm{NO}_{x}$ requirements of 42 and $65 \mathrm{ppm}$, respectively. The site design conditions are $32^{\circ} \mathrm{C}$ $\left(90^{\circ} \mathrm{F}\right)$ and $50 \%$ relative humidity at an elevation of $270 \mathrm{~m}$ ( 884 feet) above sea level.

Initial hot commissioning began with liquid fuel only on the first two units in April 1994 since construction of the natural gas pipeline was not complete. Operational and hardware related difficulties delayed commercial operation and resulted in a major inspection of one of the units. During this inspection the compressor bearing was found to be moderately wiped, where upon the OEM made the decision to have the bearing repoured. The failure mode assessment was not conclusive, two possibilities were considered to be potentially the root cause, either high loading, or contaminated lube oil. The machine was reassembled with the repaired bearing which failed during the first idle speed

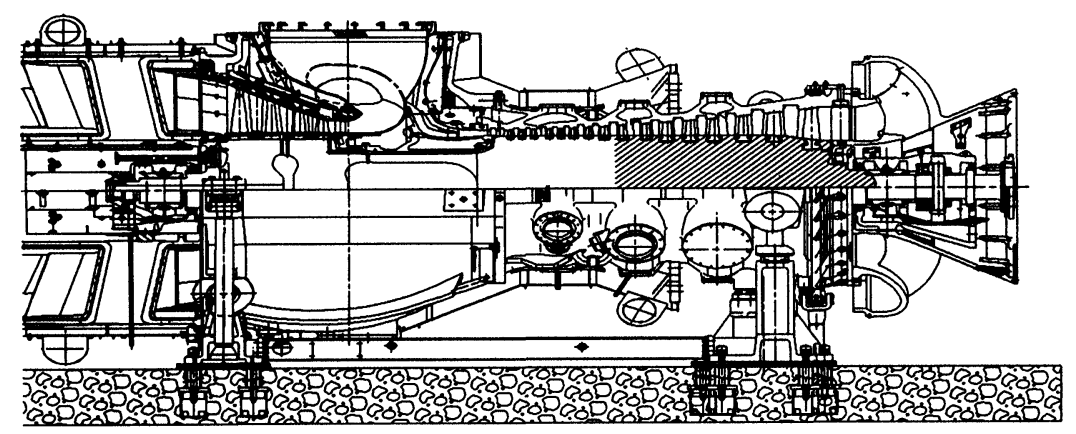

FIGURE 1 GT11N2. 
attempt during recommissioning. Inspection of the bearing revealed heavy wiping. Again, the cause was unclear, either poor quality pour of the repaired bearing, or again contaminated lube oil was judged to be the cause.

By this time hot commissioning of the second unit on gas fuel was well under way with base load optimization runs being attempted. During these runs high bearing metal temperature alarms and associated protective load shedding were observed, as well as unexpected temperature differences between the two axially spaced thermocouples of individual bearing shells. The same behavior eventually was seen in the first unit as well. Additionally, the third unit experienced two compressor bearing failures during its initial hot commissioning before achieving base load. In both cases it was determined that high loading was a contributing factor but not likely to be the root cause.

As not only the E.W. Brown GT11N2 units were in the commissioning phase, a considerable amount of starts were amassed during a short period of time, and six compressor bearing failures manifested in babbitt wiping in three individual units within a total of 224 start stop cycles. An overview of starts and failures before and after rectification of the problem is given in Table I. Apparently, looking at the overall picture contaminated lube

TABLE I Starts and operating hours before and after jacking oil system modification

\begin{tabular}{lccccc}
\hline \multirow{2}{*}{ Unit } & \multicolumn{3}{c}{ Jacking oil system (new $\equiv$ additional) } \\
\cline { 2 - 3 } & \multicolumn{2}{c}{ Starts } & & \multicolumn{2}{c}{ Operating hours } \\
\cline { 2 - 3 } \cline { 5 - 6 } & Old & New & & Old & New \\
\hline 1 & 71 & 66 & & 381 & 265 \\
2 & 69 & 57 & & 310 & 228 \\
3 & 7 & 82 & & 10 & 363 \\
4 & 0 & 53 & & 0 & 221 \\
5 & 11 & 59 & & 39 & 356 \\
6 & 16 & 61 & & 56 & 303 \\
7 & 50 & 64 & & 192 & 302 \\
8 & 0 & 87 & & 0 & 1506 \\
9 & 0 & 78 & & 0 & 1018 \\
10 & 0 & 79 & & 0 & 1578 \\
Total & 224 & 686 & 988 & 6140 \\
\hline
\end{tabular}

oil statistically could not be the root cause for the failures on all units involved.

\section{BEARING INVESTIGATIONS AND SOLUTION}

The bearing is an ABB design, low power loss, single horizontal feed bearing. It is similarly shaped to a lemon shape bearing and has one pocket at the bottom to lift the rotor with jacking oil during low rotational speeds.

The specific loading of the bearings, around $3 \mathrm{MPa}$ (435 psi) is considerable, however, the OEM's long term experience on gas as well as on steam turbines clearly indicated this load to be bearable. This is partially possible because of the high grade babbitt used as a standard which corresponds to at least an ASTM Grade 3 type of material. In order to re-check the journal bearing characteristics and the material loading, the pressure distribution within the bearing clearance was calculated for the dimensions of the bearing with an in-house code based on Glieniecke (1970). The specific steady state load case, and transient speed conditions were considered. Typical pressure distributions are shown in Fig. 2 for two speeds. At nominal speed the maximum pressure is clearly below allowable compression stresses for the babbitt.

Scrutinizing available temperature trend data logs indicated temperature spikes as shown in Fig. 3 during start up or coast down for several failed bearings. Therefore, the oil film for various rotor speeds has been calculated, and the maximum pressure as well as the minimum clearance can be plotted against speed. To prove these theoretical values, tests in the spin pit of the OEM have been done. The journal bearing of a full size GT11N2 rotor was instrumented with eddy current and pressure probes.

As very small displacement deviations were attempted to be measured, and the probes were subject to thermal drifts (no temperature compensation) no absolute values could be measured reliably over the time of the runs. However, film 

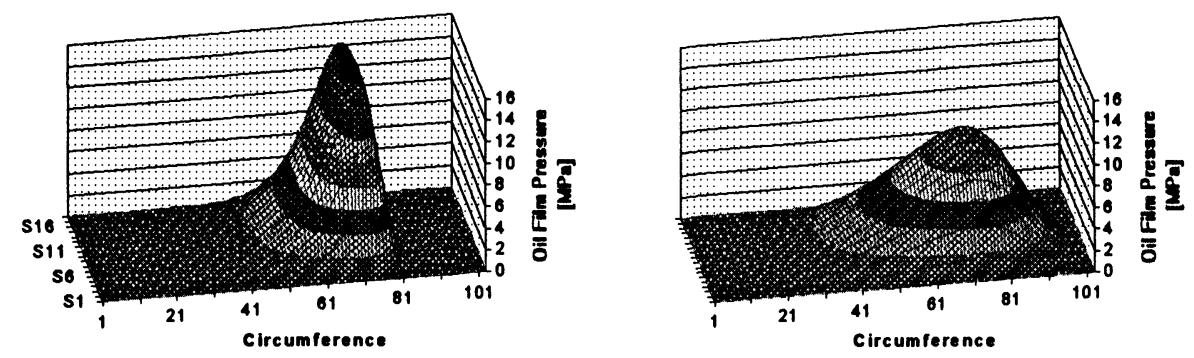

FIGURE 2 Journal bearing pressure distribution at $270 \mathrm{rpm}$ (left) and $2600 \mathrm{rpm}$ (right).

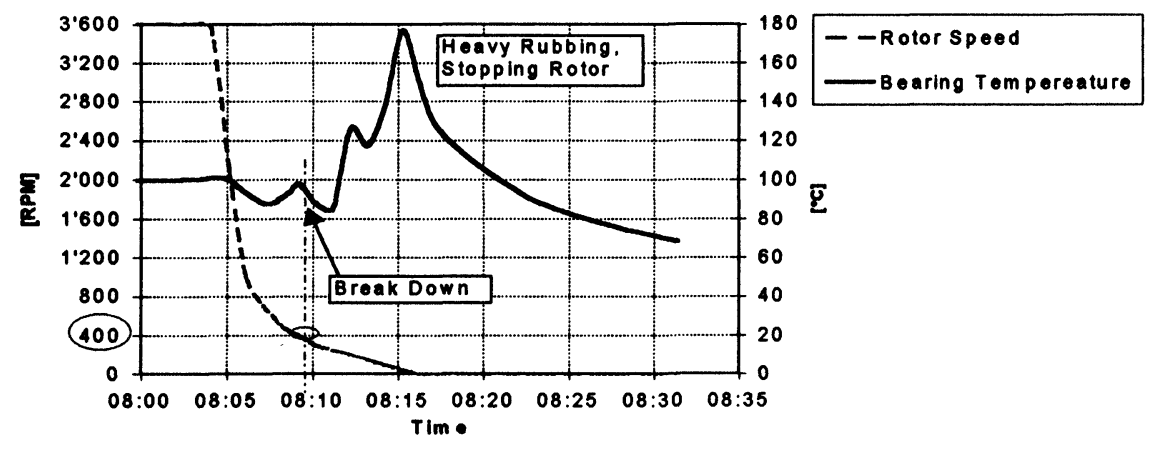

FIGURE 3 Temperature spike during coast down.

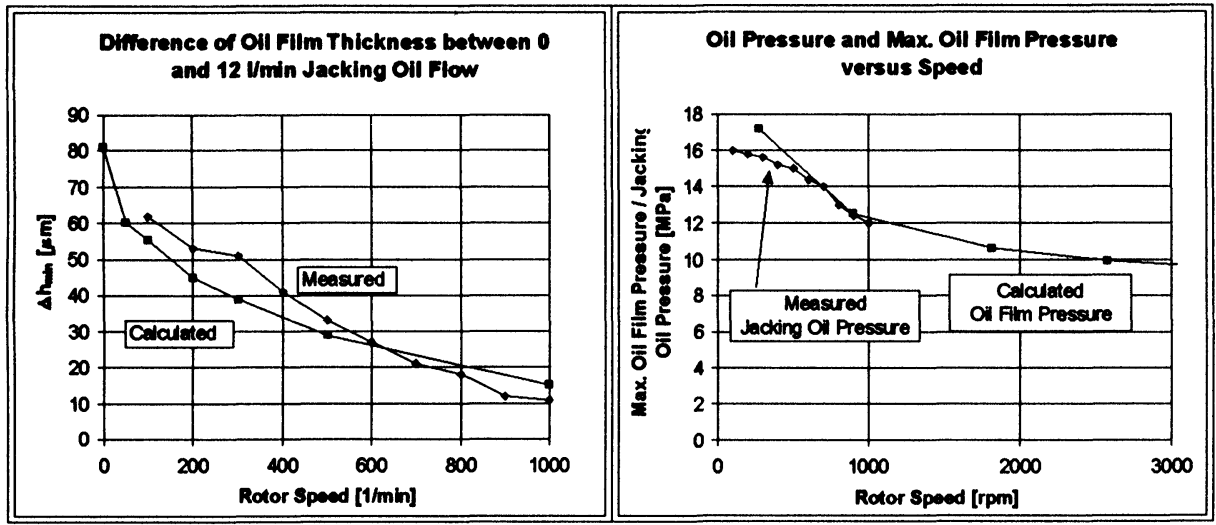

FIGURE 4 Typical relative clearance and pressure measurement.

thickness changes with controlled changes of jacking oil flow in a short time span were easily arrived at. Additionally, the oil film pressure as a function of speed was recorded.

Figure 4 indicates how well the change in predicted clearance matches the measured difference in clearance as a function of rotor speed and jacking oil flow. With 121/min (3.2 gpm) jacking oil flow the minimum oil film thickness can be increased by $30-40 \mu \mathrm{m}(1.2-1.6 \mathrm{mils})$ at $400-$ $500 \mathrm{rpm}$, and more below those speeds.

For reason of balance, the maximum oil film pressure cannot exceed the jacking oil pressure within the bearing pocket. The second half of 
Fig. 4 shows nicely how the jacking oil limits the maximum oil film pressure at speeds below $500 \mathrm{rpm}$ as it prevents the minimum bearing clearance to be further reduced. On the other hand, measurement matches the calculated film pressures well at higher speeds, where the jacking oil supply flow is not sufficient to maintain the required high pressure in the pocket anymore (there is an orifice between the line of supply and the bearing pocket).

Hence, sufficient jacking oil flow at an adequate pressure level not only maintains a minimum oil film thickness at low rotational speeds but it also limits peak pressure loading of the babbitt.

As discussed with other bearing manufacturers and the author of Glienicke (1970), a minimum film thickness of about $20-30 \mu \mathrm{m}(0.8-1.2$ mils $)$ has to be maintained to ensure safe operation of a journal bearing without scratching or even wiping the babbitt, even if fine lube oil filters are in use. Additionally, even a high grade babbitt will not sustain the excessive oil film peak pressure loading which occurs in the absence of sufficient jacking oil flow at low rotational speeds for a highly loaded bearing.

The jacking oil supply of the new auxiliary system for the GT11N2 units hence has been checked. With effectively less than $0.71 / \mathrm{min}(0.2 \mathrm{gpm})$ the flow, and therefore the minimum clearance was found to be marginal, leading to the experienced $2.7 \%$ start/ stop failures. Evaluation of the investigations performed led the OEM to reset the jacking oil flow to $61 / \mathrm{min}(1.6 \mathrm{gpm})$, and thereby increasing the minimum film thickness by more than $20 \mu \mathrm{m}$ ( 0.8 mills) at low speeds. Modifications were done on all existing units.

After the rectification, and by the time this article was written, the GT11N2 fleet had accumulated more than three times the start stop cycles (and more than six times the fired hours) than with the marginal jacking oil flow without one new failure of the bearing babbitt; see Table I.

From those statistics it hence can be concluded that energy efficient, highly loaded bearings are safe during steady state operation at nominal speed. No further failures have to be expected if sufficient care is taken during start up and coast down conditions, i.e., if sufficient jacking oil flow is available during low transient rotational speeds.

\section{BLADE INCIDENT WITH FAULT CONDITION UNBALANCE}

During a test run intended to observe the above mentioned bearing behavior on one of the KU units the machine was approaching base load when it tripped on very high vibration. The fire which ensued in the machine's enclosure and exhaust ductwork was extinguished quickly and safely by the $\mathrm{CO}_{2}$-system. A visual inspection revealed that no parts were ejected from within the machine, but considerable damage to the turbine/generator set such as broken lube oil line connections (leading to the fire), slight movement, broken journal bearings, and failure of the generator exciter support had occurred. A cursory examination from the exhaust end of the turbine revealed that several last row blades had failed. The OEM issued a stop run order while an investigation and failure analysis was performed.

The root cause of the excessive unbalance was identified to be two failed last stage blades. Detailed investigation of the telemetric measurement taken on these blades in conjunction with metallographical investigations of the fracture surface and Finite Element Method (FEM) stress and modal analysis revealed a rather surprising effect. While this blade row was not in resonance with any engine rotating frequency harmonic, both, its first and second natural frequencies were subject to unusually high, though not excessive stochastic excitation. Individual resulting stress amplitudes had been analyzed before and were clearly within acceptable limits, i.e., by far not sufficient for a high cycle fatigue (HCF) failure. However, the second frequency proved to be almost exactly an integer multiple of the first one. Additionally, the modal FEM analysis indicated that the two mode shapes were resulting in a maximum stress amplitude at 
almost the identical location in the airfoil trailing edge to platform transition. This coincidence sporadically led to the stress amplitudes to add arithmetically rather than statistically at approximately the lower natural frequency period in an area of considerably high mean stresses where the centrifugal load of a last stage blade acts in the vicinity of a notch. Hence, the failure only took place after a number of fired hours untypically high for HCF.

Metallographical analysis of the failed surface as well as available material property data proved the failure scenario of HCF with high mean stress. With this insight, the design change in the critical but very limited blade area was straight forward, the two frequencies were detuned and the mean stress was lowered. Again, Table I clearly proves the success of the design change with the number of operating hours, i.e., "old, Unit 1" until failure as compared to "new, Unit 8 through 10", the latter units being originally supplied with the modified last stage blade.

The two failed blades were reflected by the casing, and, in a domino-like effect damaged other blades in their vicinity to various extents. The resulting total equivalent blade out was around 10 neighboring blades, see Fig. 5, an unbalance that most industrial gas turbine rotors would not be capable of carrying without major destruction Florjancic et al. (1997).

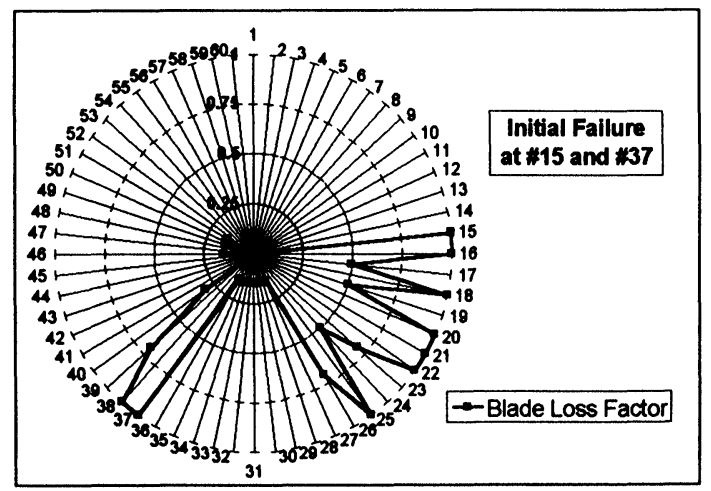

FIGURE 5 Unbalance by blade loss in the last turbine stage.
As the machine was opened for analysis and repair, it became apparent that the gas turbine rotor had survived the extremely large imbalance incident very well. Even though considerable rubbing had occurred in the compressor section it resulted in relatively minor damage to the rotor. The surface rubbing and some burrs were rectified easily. However, it also became apparent that improvement to the existing structure, mainly auxiliary piping, was possible and could be implemented with reasonable effort.

Increasing the rigidity of the broken generator exciter support again was straight forward with additional and stronger bolting to sustain loads much higher than originally anticipated. The auxiliary piping was further investigated. Apparently, a balance between distance of supports, piping flexibility, and attached masses (flanges) had to be found. The design of such "low tech" but very obviously still essential items has therefore been investigated in very detail. Design principles were improved to an outlay as insensitive as possible to very high transient excitations, although they only occur during uncommon but extreme fault conditions. It was found that designs can be established which will withstand the extreme loading of a last stage failure but that such piping will need thorough inspection in the aftermath, as the endurance limit almost certainly will be exceeded during such an event, i.e., such high loading can be sustain for a limited number of cycles, only.

Rectifying design principles after such an event certainly does lead to an overall improved product safety. However, the need for a comprehensive understanding and prove of the theoretical background of rotordynamics coupled to structural dynamics was strongly felt after the incident. The OEM and the owner of the gas turbines therefore decided to undertake a joint effort to establish baseline rotor- and structural dynamic base line data of the units as installed on site. This investigation was seen as a unique possibility to check and prove design parameters, a task impossible to fulfill with high accuracy on a test stand. With the owners 
best interest to fully understand his equipment, and hence, with his full support the following investigation could be undertaken.

\section{MEASUREMENT OF GAS TURBINE ROTOR AND STRUCTURAL DYNAMICS}

Figure 6 shows all measurement locations along the rotor train as defined by the OEM. Bearings are numbered 1 through 6 , starting at the turbine end. For a better assessment of mode shapes, the location at the intermediate shaft (spool) was chosen in addition to standard locations at bearings. Special attention was also given to the two bearing locations of the gas turbine itself. Here, shaft measurements were taken inboard and outboard of the bearing, to avoid inaccurate measurement in potential mode shape nodes around the bearing, and to assess shaft to stator alignment during operation. The movement of the bearing shell relative to its support structure was measured in bearing 1, planes 4 and 5 .

The displacement measurements of bearing 1, planes 2, 4 and 5, of bearing 2, plane 2, and of the intermediate shaft and generator in general are nonstandard. An additional non-standard measurement is the absolute vibration at the intermediate shaft location which was introduced to gain full relative and absolute vibration characteristics along the entire rotor train. Hence, extensive instrumentation and wiring was needed. This part of the project was executed by the owner, with his own staff on site. He also installed a measurement trailer adjacent to the gas turbine enclosure, to which he led all, standard and non-standard vibration measurement channels.

Measurement and data reduction itself was contracted to Bently Nevada Corporation (BNC). The OEM specified the locations and type of measurement needed, and $\mathrm{BNC}$ was responsible to establish the measurement hardware set-up, data storage and reduction, as well as to perform the entire measurement. During the measurement, the owner was operating the unit jointly with OEM commissioning staff. Special care had to be taken, as deliberately large trial unbalance weights were installed alternatively on both sides of the gas turbine to assess its characteristic behavior.

\subsection{Measurement Equipment}

The transducer suite for this investigation, consisted of proximity probes, velocity seismic transducers, and thermocouples. The additional proximity probes in planes 2 of Bearing \#1 and \#2 allowed to evaluate the actual rotor position angle with respect to the vertical direction and the eccentricity ratio at midspan of both turbine bearings. Planes 4 and 5 of Bearing \#1 were introduced to measure the "tilting" of the bearing liner against the housing during operation. The velocity seismic transducers measure the absolute motion of the bearing housing at both Bearings \#1 and $\# 2$, while thermocouples were used to measure bearing metal temperatures and cooling air temperature in four of the support struts for Bearing \#1.

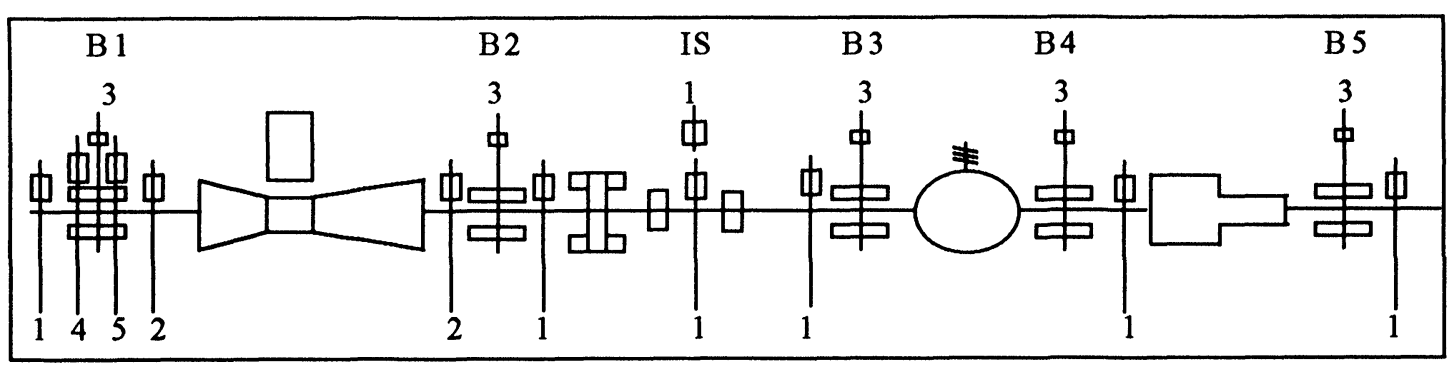

FIGURE 6 Measurement set-up. 
Shaft relative vibration measurements at Bearings \#1 and \#2, as well as bearing liner to bearing housing relative displacement measurements at Bearing \#1, were obtained with a permanently installed BNC proximity probe transducer system. Transducer calibration was consistent with BNC specifications of $7.9 \mathrm{mV} / \mu \mathrm{m}(200 \mathrm{mV} / \mathrm{mil}), \pm 5 \%$. Frequency response characteristics for proximity probes are often stated as DC (zero frequency) to $10,000 \mathrm{~Hz}(600,000 \mathrm{cpm})$. However, at higher frequencies, displacement amplitudes are quite small, and typically fall below the signal to noise ratio of the measurement system. For this reason, the most significant data from proximity probes occurs in the frequency domain of DC to $1,500 \mathrm{~Hz}$ $(90,000 \mathrm{cpm})$.

Bearing housing absolute velocity measurements were made at Bearings \#1 and \#2 with permanently installed seismic transducer systems. Transducer calibration was within the nominal manufacturer's specifications of $19.7 \mathrm{mV} / \mathrm{mm} / \mathrm{s}(500 \mathrm{mV} / \mathrm{in} / \mathrm{s})$, with a useable frequency response of from 10 to $1,000 \mathrm{~Hz}$ $(600-60,000 \mathrm{cpm})$. The housing absolute velocity data was integrated to displacement and then post processed with the shaft relative data to obtain shaft absolute motion.

One permanently installed proximity transducer was used as the once per revolution trigger probe. It is installed at $0^{\circ}$ at the turbine to intermediate shaft coupling.
The vibration transducers are named to provide the location of the transducer along the machine train, i.e. Bearings \#1 and \#2 etc., and the angular orientation of the transducer, i.e. $\mathrm{Y}\left(45^{\circ} \mathrm{L}\right)$ or $\mathrm{X}$ $\left(45^{\circ} \mathrm{R}\right)$.

The transducer convention adopted by the owner is to view the machine train from the driven machine (generator) looking back to the driver (gas turbine). Using this convention, rotation is in clockwise $(\mathrm{CW})$ direction. At all five bearings, the $\mathrm{Y}$ transducer is mounted at $45^{\circ}$ left from $0^{\circ}$ (top dead center), and the $\mathrm{X}$ transducer is mounted $45^{\circ}$ right from $0^{\circ}$. One must maintain this convention, i.e. a true Cartesian coordinate system, where the $+Y$ axis (vertical transducer) is always $90^{\circ}$ counterclockwise of the $+X$ axis (horizontal transducer), in order to properly evaluate the vibration response data. A transducer overview for Bearing \#1 and Bearing \#2 is exhibited in Fig. 7.

\subsection{Data Processing Instrumentation}

All steady state and transient startup and shutdown vibration response data was obtained via ten BNC 208 Data Acquisition Instrument Units (DAIU). Two units were paired to form a 16 channel digital, real time, data acquisition package. Five 16 channel instrumentation grade digital tape recorders were installed to provide taped backup data. All vibration and process variable data was acquired by BNC's Machinery Diagnostic Services personnel.

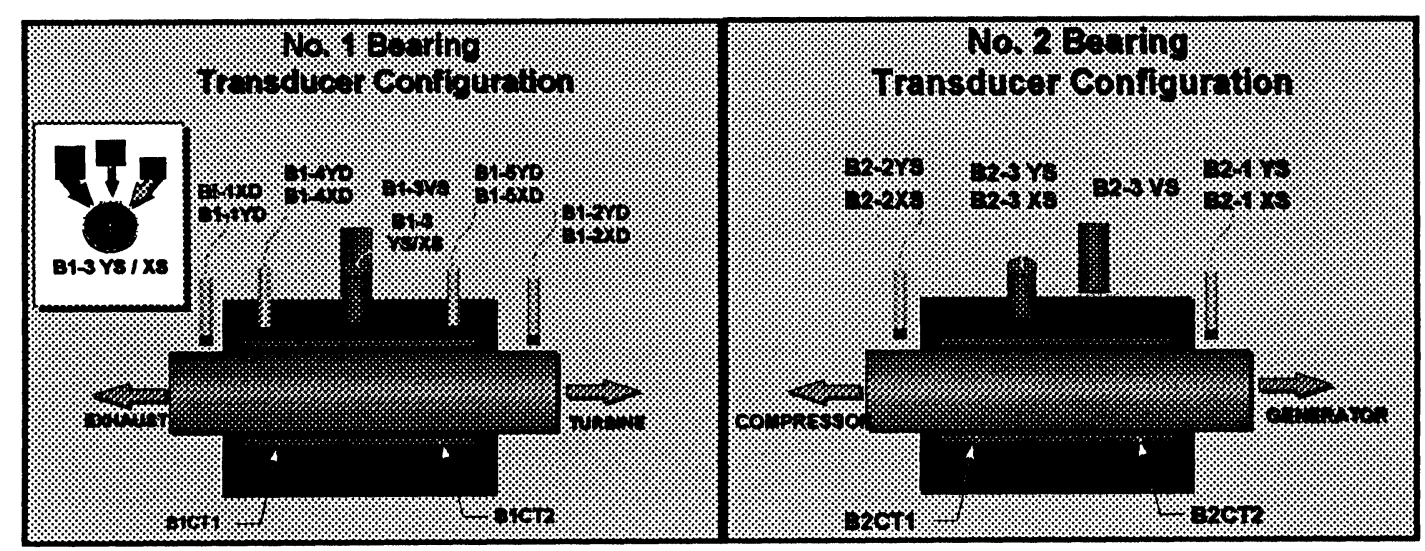

FIGURE 7 Bearing \#1 (turbine side); Bearing \#2 (compressor side). 
TABLE II Comparison of measured and calculated bearing and structural support characteristics

\begin{tabular}{|c|c|c|c|c|c|c|c|c|c|c|c|}
\hline \multirow[t]{3}{*}{ Brg. } & \multicolumn{4}{|c|}{ Bearing stiffness $\times 10^{9}$} & \multicolumn{3}{|c|}{ Bearing damping $\times 10^{6}$} & \multicolumn{4}{|c|}{ Structural stiffness $\times 10^{9}$} \\
\hline & \multicolumn{2}{|c|}{$\mathrm{BNC}$} & \multicolumn{2}{|c|}{$\mathrm{ABB}$} & \multirow{2}{*}{$\frac{\mathrm{BNC}}{\text { Nom. }}$} & \multicolumn{2}{|c|}{$\mathrm{ABB}$} & \multicolumn{2}{|c|}{$\mathrm{BNC}$} & \multicolumn{2}{|c|}{$\mathrm{ABB}$} \\
\hline & $\begin{array}{l}\text { Vert. } \\
(\mathrm{N} / \mathrm{m})\end{array}$ & $\begin{array}{l}\text { Horiz. } \\
(\mathrm{N} / \mathrm{m})\end{array}$ & $\begin{array}{l}\text { Vert. } \\
(\mathrm{N} / \mathrm{m})\end{array}$ & $\begin{array}{l}\text { Horiz. } \\
(\mathrm{N} / \mathrm{m})\end{array}$ & & $\begin{array}{c}\text { Vert. } \\
\text { (Ns/m) }\end{array}$ & $\begin{array}{l}\text { Horiz. } \\
(\mathrm{Ns} / \mathrm{m})\end{array}$ & $\begin{array}{l}\text { Vert. } \\
(\mathrm{N} / \mathrm{m})\end{array}$ & $\begin{array}{l}\text { Horiz. } \\
(\mathrm{N} / \mathrm{m})\end{array}$ & $\begin{array}{l}\text { Vert. } \\
(\mathrm{N} / \mathrm{m})\end{array}$ & $\begin{array}{l}\text { Horiz. } \\
(\mathrm{N} / \mathrm{m})\end{array}$ \\
\hline 1 & 1.1 & 0.7 & $3.8-4.0$ & $1.4-1.5$ & 5.3 & $14-15$ & $2.4-2.5$ & 5.3 & 3.5 & 2.2 & 0.8 \\
\hline 2 & 2.6 & 1.4 & $5.2-6.1$ & $1.8-2.0$ & 7 & $19-22$ & $3.2-3.5$ & 10.5 & 7.9 & 6.7 & 2.2 \\
\hline 3 & 1.6 & 1.4 & $1.4-1.9$ & $0.6-0.8$ & 3.5 & $5.8-7.6$ & $1.0-1.3$ & 8.8 & 7.0 & & \\
\hline 4 & 1.2 & 0.53 & $1.1-1.5$ & $0.4-0.6$ & 3.5 & $4.5-6.0$ & $0.8-1.0$ & 8.8 & 7.0 & & \\
\hline 5 & 0.02 & 0.01 & $0.2-1.3$ & $0.03-0.2$ & 0.9 & $0.6-1.2$ & $0.1-0.2$ & 0.2 & 0.04 & & \\
\hline
\end{tabular}

TABLE III Comparison of measured and calculated critical speeds

\begin{tabular}{|c|c|c|c|c|c|c|c|c|c|c|c|c|c|c|}
\hline \multirow{3}{*}{$\begin{array}{l}\text { Modal } \\
\text { range }(\mathrm{cpm})\end{array}$} & \multicolumn{5}{|c|}{ BNC measurement data } & \multicolumn{5}{|c|}{ Stability analysis } & \multirow{2}{*}{\multicolumn{4}{|c|}{$\begin{array}{l}\text { Response analysis } \\
\text { Active component }\end{array}$}} \\
\hline & \multirow[t]{2}{*}{ DAMP } & \multicolumn{4}{|c|}{ Active component } & \multirow[t]{2}{*}{ DAMP } & \multicolumn{4}{|c|}{ Active component } & & & & \\
\hline & & GT & IS & GE & EX & & GT & IS & GE & EX & GT & IS & GE & EX \\
\hline $450-500$ & $3-7$ & $\mathrm{x}$ & & & & Structura & node & & & & & & & \\
\hline $800-950$ & $9-12$ & $\mathrm{x}$ & $\mathrm{x}$ & $\mathrm{x}$ & $\mathrm{x}$ & Structur & mode & uple & & & $\mathrm{x}$ & $\mathrm{x}$ & $\mathrm{x}$ & $\mathrm{x}$ \\
\hline $1050-1200$ & $6-10$ & $\mathrm{x}$ & $\mathrm{x}$ & & $\mathrm{x}$ & $15-18$ & & & $\mathrm{x}$ & $\mathrm{x}$ & $\mathrm{x}$ & $\mathrm{x}$ & $\mathrm{x}$ & $\mathrm{x}$ \\
\hline $1300-1500$ & $9-12$ & $\mathrm{x}$ & $\mathrm{x}$ & & & Structur & mode & & & & $\mathrm{x}$ & $\mathrm{x}$ & $\mathrm{x}$ & $\mathrm{x}$ \\
\hline $1600-1850$ & $8-21$ & $\mathrm{x}$ & $\mathrm{x}$ & $\mathrm{x}$ & & $16-17$ & $\mathrm{x}$ & $\mathrm{x}$ & & & & $\mathrm{x}$ & $\mathrm{x}$ & \\
\hline $2000-2200$ & 30 & & & $\mathrm{x}$ & & $37-58$ & & & $\mathrm{x}$ & $\mathrm{x}$ & $\mathrm{x}$ & $\mathrm{x}$ & $\mathrm{x}$ & $\mathrm{x}$ \\
\hline $2400-2700$ & $3-27$ & $\mathrm{x}$ & & $\mathrm{x}$ & $\mathrm{x}$ & $24-25$ & & $\mathrm{x}$ & $\mathrm{x}$ & $\mathrm{x}$ & & $\mathrm{x}$ & $\mathrm{x}$ & \\
\hline $2800-3100$ & $3-7$ & $\mathrm{x}$ & & & $\mathrm{x}$ & $17-18$ & $\mathrm{x}$ & $\mathrm{x}$ & & $\mathrm{x}$ & $\mathrm{x}$ & $\mathrm{x}$ & $\mathrm{x}$ & $\mathrm{x}$ \\
\hline
\end{tabular}

The DAIU is an eight channel instrument that captures and processes simultaneous vector and waveform data for each channel. A vector data record consists of five types of information:

(1) Direct (overall) vibration amplitude.

(2) $1 \mathrm{X}, 2 \mathrm{X}, n \mathrm{X}$ amplitude.

(3) Gap voltage.

(4) Machine speed (rpm).

(5) Time.

The sampling rate was 128 samples/revolution with a discrete sample occurring over 8 revolutions (1024 samples) for the machine speed at hand. Each acquisition unit (pair) was connected to a 486 notebook computer, with a total of five systems, 80 measurement channels were available. The vibration/process variable data acquisition was accommodated via the five data acquisition sys- tems. Each data acquisition computer was operating with $\mathrm{ADRE}^{\circledR}$ for Windows ${ }^{(}{ }^{\circledR}$ software developed by BNC.

Measurements are compared to calculated results in the next paragraph, an overview is given in Tables II and III. More detailed information about measurement results, i.e., type of data reduction, mode shapes, extraction of structural response due to unbalance, etc., is beyond the scope of this publication and can be found in Florjancic et al. (1998).

\section{LINEAR ROTORDYNAMICS}

Measured results were compared to originally calculated natural frequencies and forced response runs, based on the model shown in Fig. 8. To cover uncertainties, the support stiffness (structure and 


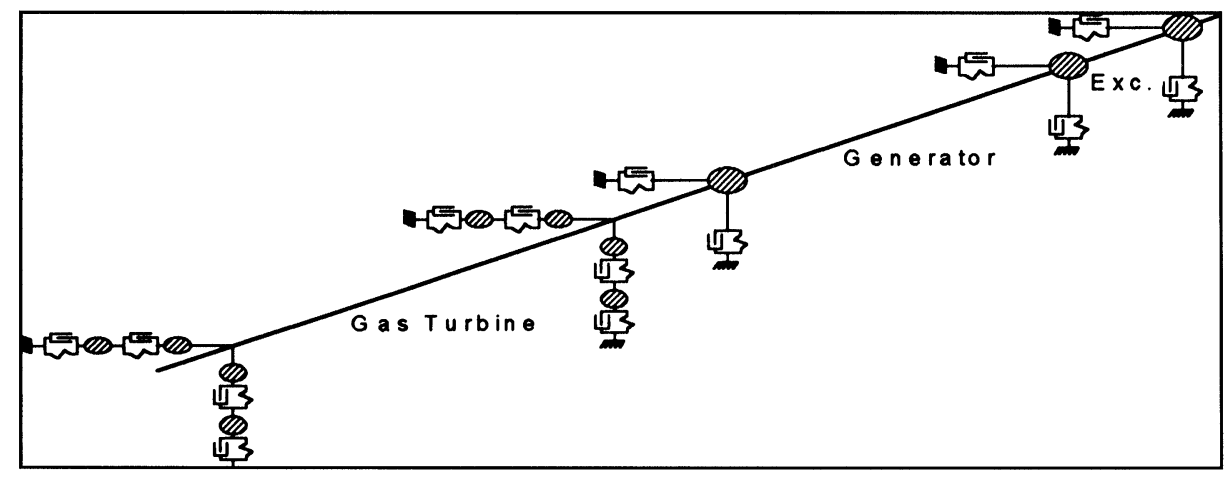

FIGURE 8 Standard rotordynamic model.

bearing in series) of the rotordynamic model is varied in a sensitivity study over a considerable range, i.e., typically from $10^{8}$ to $10^{9} \mathrm{~N} / \mathrm{m}\left(6 \cdot 10^{5}\right.$ $\left.6 \cdot 10^{6} \mathrm{lbs} / \mathrm{in}\right)$. Individual properties derived from the unbalance measurements compare well with those combined values. More detailed stiffness estimates based on a Finite Element (FE) model of the gas turbine support structure had been provided to allow BNC to assess measurement more easily. The calculated values correspond well with the measured ones, as can be seen in Table II. NB.: Measured properties of Bearings \#3 through 5 are less reliable as unbalance excitation has only been applied to the gas turbine part of the rotor train.

Discrepancies in bearing stiffness and damping are in the order of a factor $2-3$. They are caused to some extent by tolerances in bearing diameter and length. However, the strongest influence on parameter discrepancies result from variations in effective static load on each bearing due to non-perfect rotor train alignment (as discussed in Florjancic et al. (1998) (Fig. 8), from effectively non-parallel axes of rotor and bearing liner which is not taken into account in the theoretical prediction, and the limited accuracy of measurement data. The comparison of the parameters given clearly indicates the realistic accuracy of theoretical prediction (of a "perfect system") compared to effective machine behavior.

Differences in structural stiffnesses are somewhat larger than in bearing parameters. The extent and complexity of the support structure is considerable, including many bolted and fitted interfaces. The FE model shown in Fig. 9 is not sophisticated enough to represent exactly the effective multi-layer machine support structure. However, even a more detailed model would show discrepancies due to tolerances, and, more importantly, due to varying conditions in interfaces. Non-linearities in interfaces (friction and looseness) also change the stiffnesses according to effective pre-load, i.e., with the state of alignment. It was therefore chosen to limit the scope of the FE model, and all interfaces and their variations were not included for the analysis.

Critical speeds of the original design study were also compared to measured values. Again, as test unbalances had been put into the gas turbine rotor only, critical speeds of the generator part of the rotor train were only weakly excited and are less accurate to determine. An overview of predicted and measured critical speeds is given in Table III.

Structural modes obviously cannot be predicted by the model of Fig. 8, as the support structure is modelled only by a spring (no mass). Other natural frequencies and modal dampings compare well with the measured values. The portions of the rotor participating in the calculated and measured vibration mode shape also are closely related, considering that unbalance was placed on the gas turbine portion, only. Identifying critical speeds from forced response calculations is indicated in addition to the natural frequencies. As structural modes 


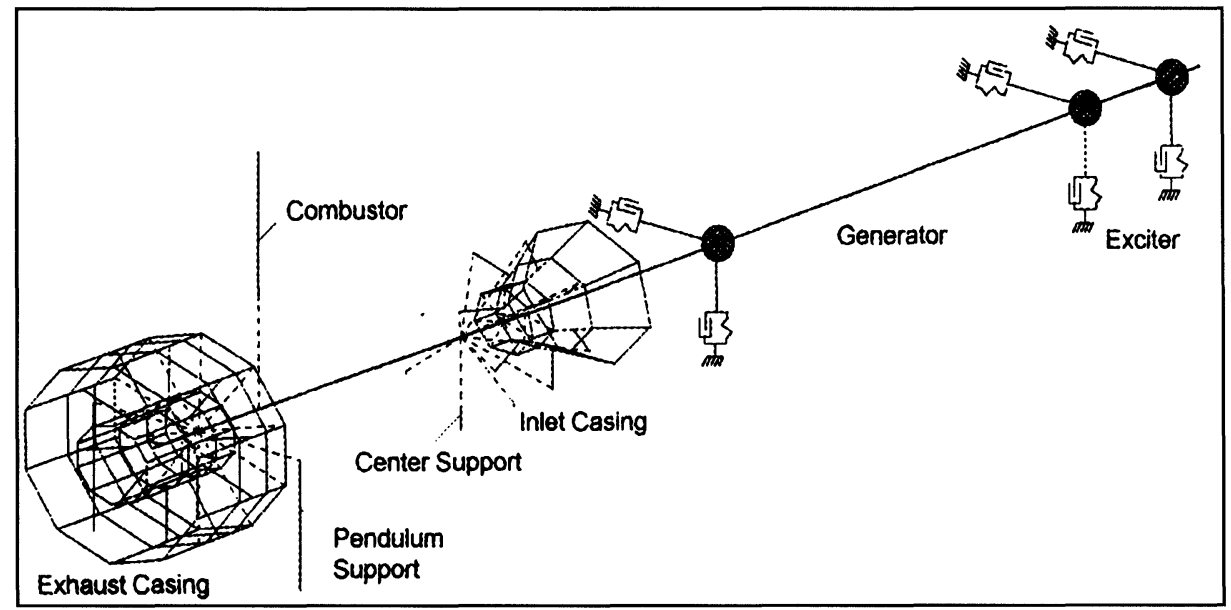

FIGURE 9 Detailed rotordynamic model.

are at low frequencies, and the rotor modes at higher frequencies, closer to the running speed, are predicted well, the simple model is sufficiently accurate to allow a safe prediction of vibrational behavior of the rotor during steady state operation and higher transient rotor speeds. At lower speed transients, accuracy is of minor importance, as forced responses are smaller.

A more detailed rotordynamic FE model of the unit was established, including the mass distribution of the stator part, i.e., the gas turbine casing and the silo combustor, as well as the FE model of the support, rather than just support stiffnesses; see Fig. 9. As expected, results compare well with the simpler model, and the measured structural mode around $1,300-1,500 \mathrm{cpm}$ is now predicted. Additional effort would have to be undertaken to fully model the multi-layer rotor-stator structure in order to predict all modes with higher accuracy, see also Florjancic et al. (1998) for discussions.

However, as the measured results indicate, the simpler assessment is of sufficient accuracy and information to assess the safe rotordynamic behavior. The overall results fully justify the judgment of predicted bearing and support parameters to be good and adequate compared to measured ones.

The detailed model was used to simulate big unbalances in the area of the last stage blade. Not surprisingly, it was found that linear rotordynamics cannot account for an unbalance as it had occurred during the blade loss incident experienced. Even the present design of an unbalance insensitive rotor, Florjancic et al. (1997), has to rely on iterative time step calculation of the non-linear bearing coefficients for unbalances exceeding the equivalent of several single blades.

A study executed in this manner indicated that information on the behavior of journal bearings with eccentricities close to one, i.e., at the beginning of oil film break down and during metal to metal contact is needed for huge unbalances but not available in literature. Additionally, it was realized that a time step coupling of rotordynamics with a non-linear structural code, one influencing the results of the other due to impacting, is needed to fully assess the consequences of a huge unbalance. A possibility to test bearings to destruction and to couple rotordynamics with non-linear structural codes has been outlined in Childs (1996), but the coupled tools are not established.

\section{CONCLUSIONS}

The joint effort of the owner and the OEM of an industrial gas turbine allowed for the successful 
solution of a field problem, and the full assessment of the rotordynamic behavior or the gas turbine as built and installed.

Detailed theoretical and experimental investigations on the journal bearings used proved that strongly loaded journal bearings work very reliably if sufficient care is taken with the according auxiliary equipment. Speed transient conditions are of primary importance, and sufficient jacking oil has to be provided in order to ensure a minimum oil film thickness. This ascertains that the local film pressure does not exceed limits acceptable for the babbitt material, that no rubbing will occur, and it additionally makes the bearing insensitive to contaminated lubrication oil. Operational history after rectification of the marginal jacking oil flow statistically proves the theoretical and experimental findings.

A blade loss incident lead to a unusually large unbalance of the gas turbine. After the safe shut down it was found that the rotor also in practice behaves as unbalance insensitive as described in Florjancic et al. (1997). Damage to the rotor was minor rubs and burrs. Structural damage to auxiliaries was of more concern, and design principles were changed to ensure that in the future such piping will safely sustain the fault conditions.

The extensive vibration measurement leading to enhanced and proven understanding of the dynamics of the rotor train was only possible as a cooperation of the owner, responsible for the infrastructure, the OEM defining the program and data needed, and the contracted vibration specialists executing the campaign and establishing appropriate data reduction methods. Comparison of the measured and reduced data with design values proved sound design tools and accuracy had been achieved. Parameters used for the modeling of the support structure were measured to be correct, and hence, the dynamic behavior of the rotor train had also been predicted with reliable accuracy.

Non-linear rotordynamics was found to be needed to assess a huge unbalance equivalent to several blades. However, tools to couple rotordynamics and the stationary components of the gas turbine under impact would be needed but are not readily available.

This entire project showed how the cooperation between owner, OEM, and subcontractors can lead to success and gain for all parties involved.

\section{Acknowledgments}

The authors wish to thank their companies and all the staff involved for the support given to write this publication, proving how well the cooperation went. Special thanks are given to R. Kellerer for his outstanding work on the journal bearings, E. Holoehr for his many rotordynamic studies, and J. McElhaney for his compilation of the comparison of calculated versus measured results.

\section{References}

Childs, D.W. (1996) An R\&D program to develop validated computer codes for predicting survival and secondary damage of combustion-gas-turbine/generator systems associated with blade-loss incidents, Texas A\&M University, College Station, Texas.

Florjancic, S.S., Franklin, W. and Lively, N. (1998) Vibration measurement techniques on an industrial gas turbine rotor, 43rd ASME Turbo Expo, Stockholm.

Florjancic, S.S., Pross, J. and Eschbach, U. (1997) Rotor design in industrial gas turbines, 42nd ASME Turbo Expo, 1997, 97-GT-75.

Glienicke, J. (1970) Experimentelle Ermittlung der statischen und dynamischen Eigenschaflen von Gleitlagern für schnellaufende Wellen - Einfluss der Schmierspaltgeometrie und der Lagerbreite, Fortschritt Berichte der VDI Zeitschriften, Reihe 1, Nr. 22, VDI-Verlag, Duesseldorf. 


\section{ait \\ ENERGY MATERIALS}

M A N E Y publishing

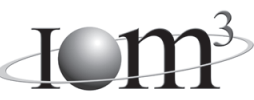

\section{Materials Science \& Engineering for Energy Systems}

Maney Publishing on behalf of the Institute of Materials, Minerals and Mining

The Institute of Materials, Minerals \& Mining

Economic and environmental factors are creating ever greater pressures for the efficient generation, transmission and use of energy. Materials developments are crucial to progress in all these areas: to innovation in design; to extending lifetime and maintenance intervals; and to successful operation in more demanding environments. Drawing together the broad community with interests in these areas, Energy Materials addresses materials needs in future energy generation, transmission, utilisation, conservation and storage. The journal covers thermal generation and gas turbines; renewable power (wind, wave, tidal, hydro, solar and geothermal); fuel cells (low and high temperature); materials issues relevant to biomass and biotechnology; nuclear power generation (fission and fusion); hydrogen generation and storage in the context of the 'hydrogen economy'; and the transmission and storage of the energy produced.

As well as publishing high-quality peer-reviewed research, Energy Materials promotes discussion of issues common to all sectors, through commissioned reviews and commentaries. The journal includes coverage of energy economics and policy, and broader social issues, since the political and legislative context influence research and investment decisions.

\section{CALL FOR PAPERS}

Contributions to the journal should be submitted online at http://ema.edmgr.com

To view the Notes for Contributors please visit: www.maney.co.uk/journals/notes/ema

Upon publication in 2006, this journal will be available via the Ingenta Connect journals service. To view free sample content online visit: www.ingentaconnect.com/content/maney

For further information please contact:

Maney Publishing UK

Tel: +44 (0)113 2497481 Fax: +44 (0)1132486983 Email: subscriptions@maney.co.uk

or

Maney Publishing North America

Tel (toll free): 8662975154 Fax: 6173546875 Email: maney@maneyusa.com

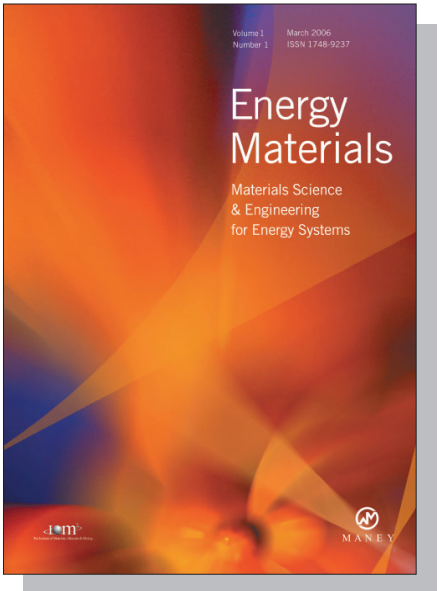

EDITORS

Dr Fujio Abe

NIMS, Japan

Dr John Hald, IPL-MPT, Technical University of Denmark, Denmark

Dr R Viswanathan, EPRI, USA

\section{SUBSCRIPTION INFORMATION}

Volume 1 (2006), 4 issues per year

Print ISSN: 1748-9237 Online ISSN: 1748-9245

Individual rate: $£ 76.00 / U S \$ 141.00$

Institutional rate: $£ 235.00 /$ US $\$ 435.00$

Online-only institutional rate: $£ 199.00 / U S \$ 367.00$

For special $\mathrm{IOM}^{3}$ member rates please email

subscriptions@maney.co.uk

\section{For further information or to subscribe online please visit www.maney.co.uk}



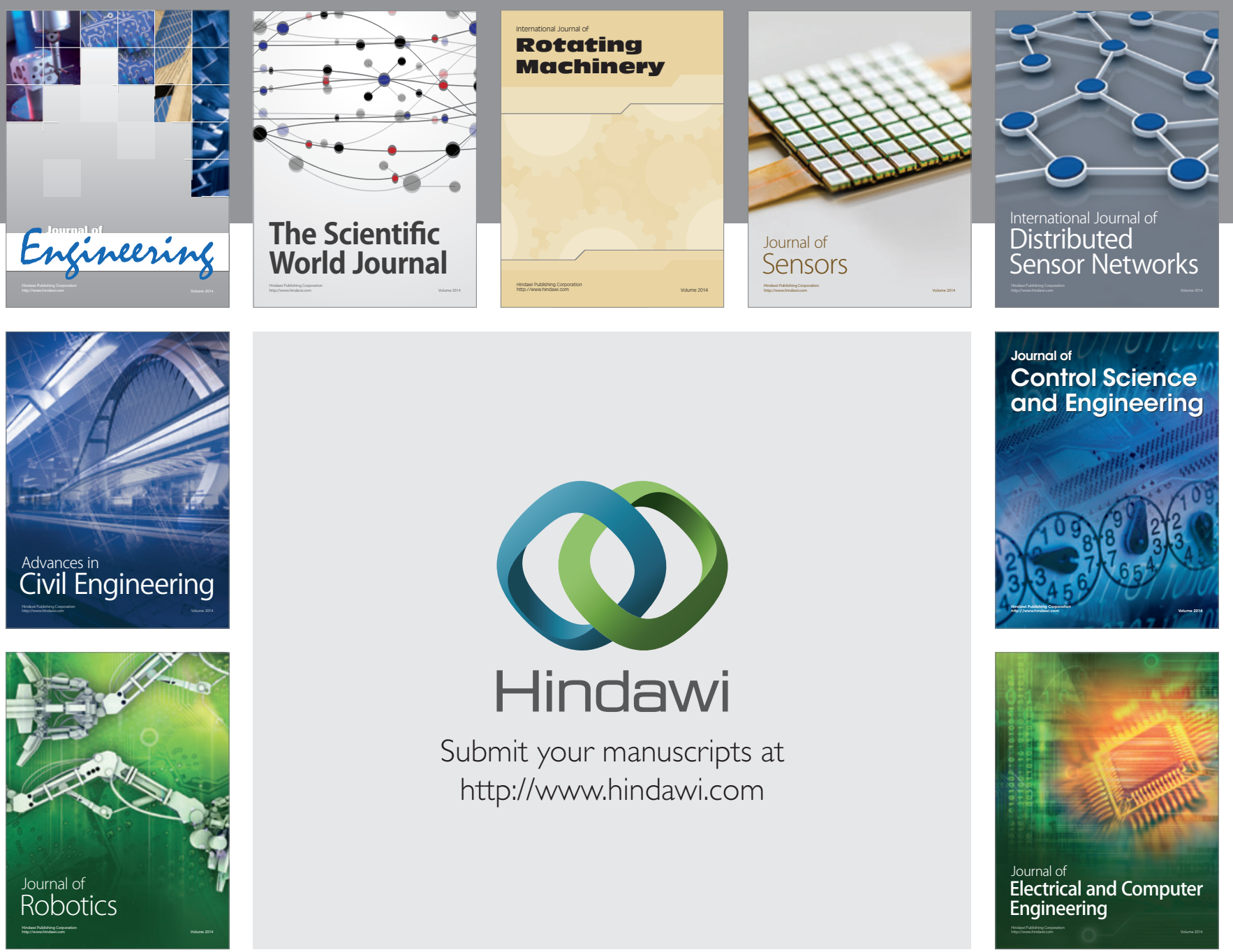

Submit your manuscripts at

http://www.hindawi.com
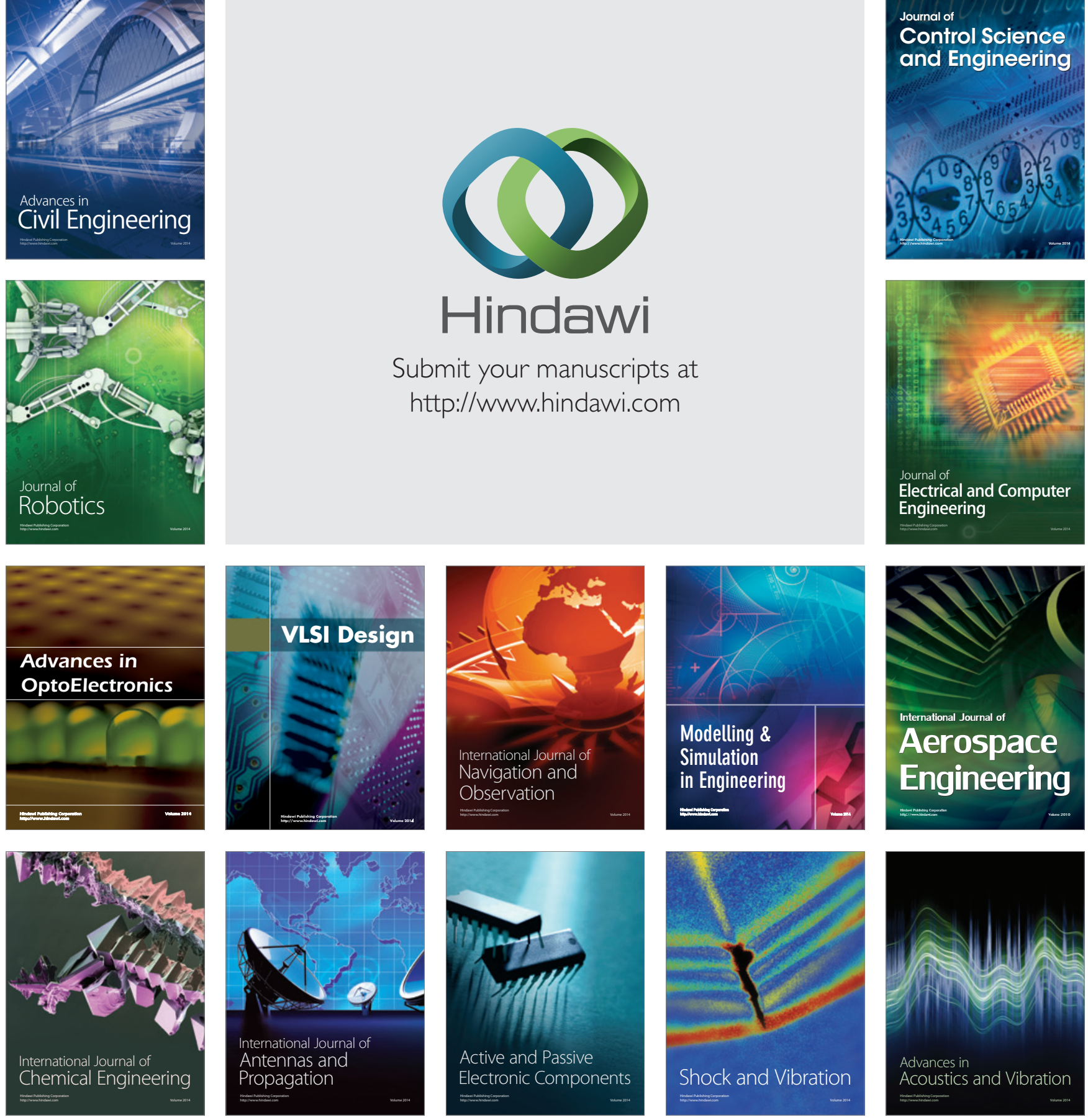